\title{
Corrigendum
}

\section{Corrigendum to "Oral Health Knowledge and Behavior among Adults in the United Arab Emirates"}

\author{
Eman Abu-Gharbieh (iD), 1,2 Basema Saddik (iD,, Mohammed El-Faramawi, ${ }^{4,5}$ \\ Samer Hamidi, ${ }^{6}$ and Mohammed Basheti ${ }^{7}$ \\ ${ }^{1}$ Clinical Sciences Department, College of Medicine, University of Sharjah, UAE \\ ${ }^{2}$ Department of Pharmacology and Toxicology, Dubai Pharmacy College, UAE \\ ${ }^{3}$ Department of Family and Community Medicine, College of Medicine, University of Sharjah, UAE \\ ${ }^{4}$ Department of Epidemiology, College of Public Health, University of Arkansas for Medical Sciences, USA \\ ${ }^{5}$ Department of Public Health, National Liver Institute, Menofiya University, Cairo, Egypt \\ ${ }^{6}$ School of Health and Environmental Studies, Hamdan Bin Mohammad Smart University, UAE \\ ${ }^{7}$ Faculty of Dentistry, Jordan University of Science and Technology, Jordan \\ Correspondence should be addressed to Basema Saddik; bsaddik@sharjah.ac.ae
}

Received 20 March 2019; Accepted 21 March 2019; Published 21 April 2019

Copyright (C) 2019 Eman Abu-Gharbieh et al. This is an open access article distributed under the Creative Commons Attribution License, which permits unrestricted use, distribution, and reproduction in any medium, provided the original work is properly cited.

In the article titled "Oral Health Knowledge and Behavior among Adults in the United Arab Emirates" [1], the name of the last author was given incorrectly as Mohammad Basheti. The author's name should have been written as Mohammed Basheti. The revised authors' list is shown above.

\section{References}

[1] E. Abu-Gharbieh, B. Saddik, M. El-Faramawi, S. Hamidi, and M. Basheti, "Oral health knowledge and behavior among adults in the United Arab Emirates," BioMed Research International, vol. 2019, Article ID 7568679, 7 pages, 2019. 


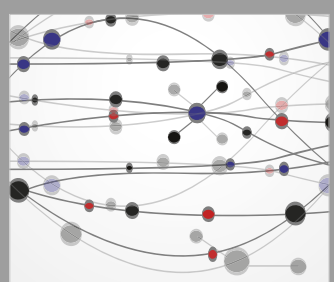

The Scientific World Journal
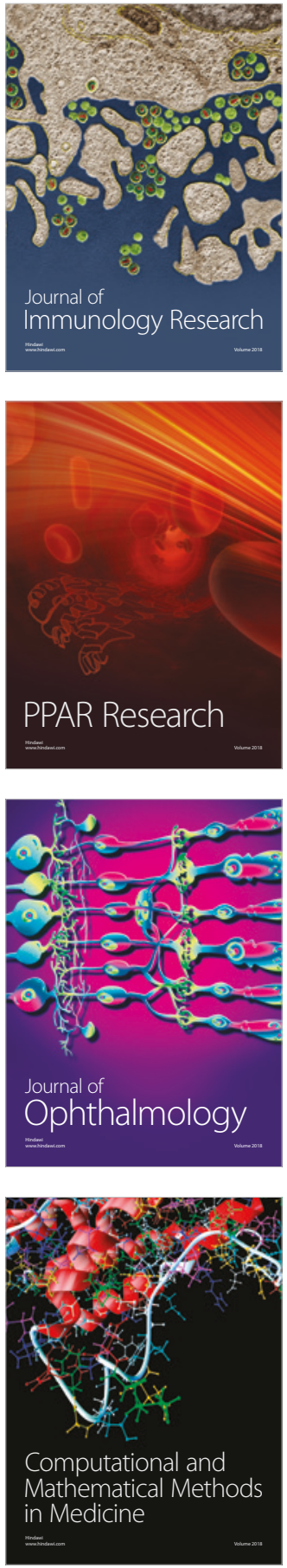

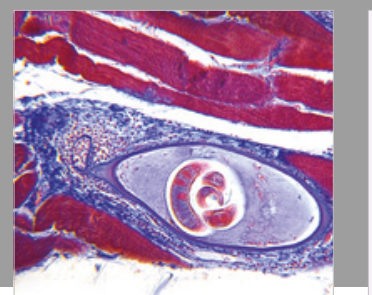

Gastroenterology Research and Practice

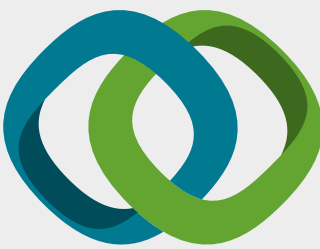

\section{Hindawi}

Submit your manuscripts at

www.hindawi.com
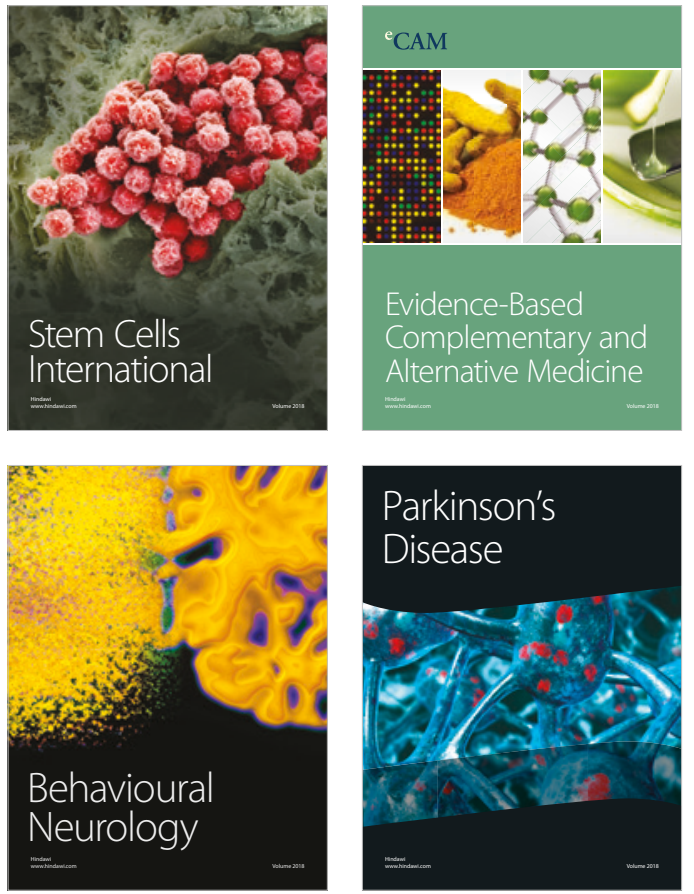

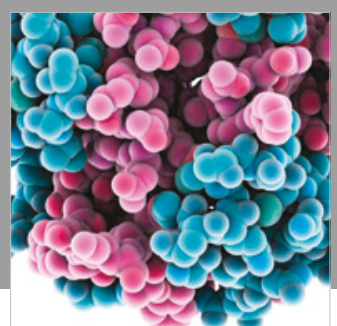

ournal of

Diabetes Research

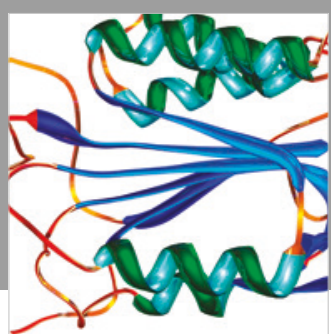

Disease Markers
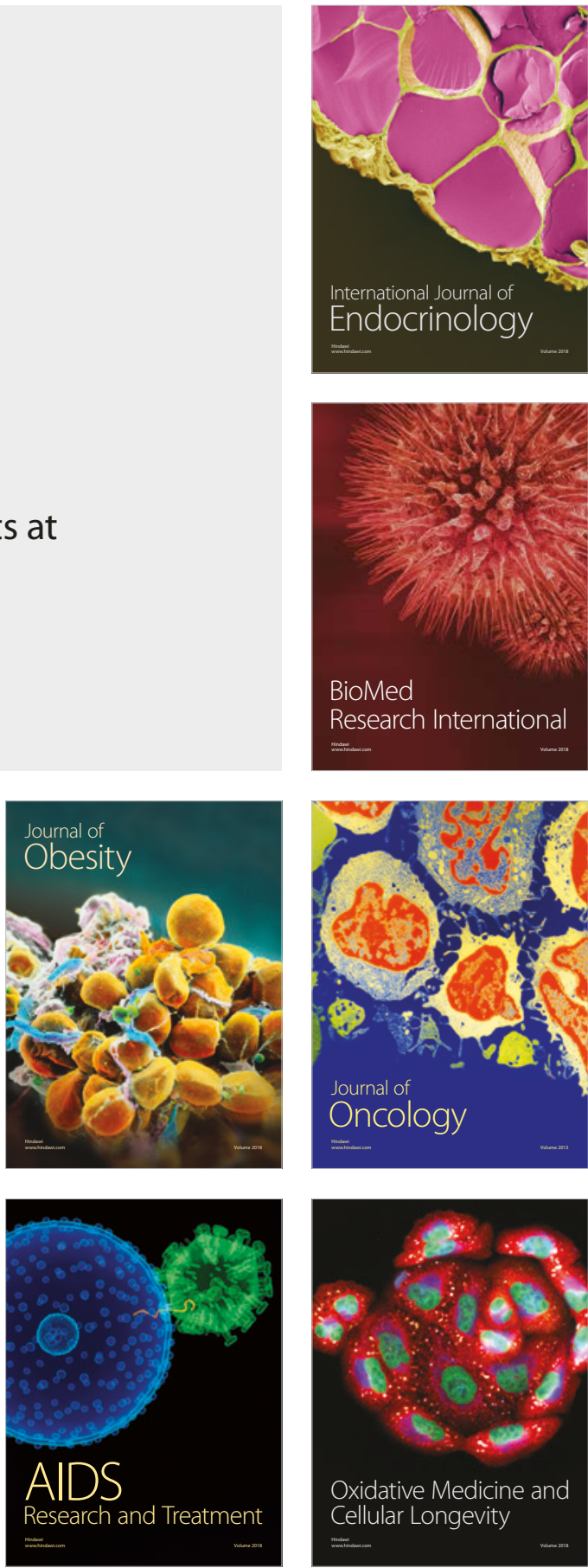